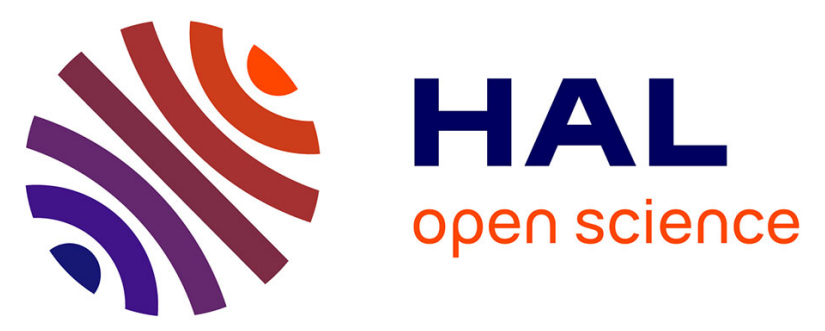

\title{
A structural study of a polymer-surfactant system in dilute and entangled regime: Effect of high concentrations of surfactant and polymer molecular weight
}

Ahmed El Aferni, Moez Guettari, Marwa Kamli, Tahar Tajouri, Alain Ponton

\section{To cite this version:}

Ahmed El Aferni, Moez Guettari, Marwa Kamli, Tahar Tajouri, Alain Ponton. A structural study of a polymer-surfactant system in dilute and entangled regime: Effect of high concentrations of surfactant and polymer molecular weight. Journal of Molecular Structure, 2020, 1199, pp.127052. 10.1016/j.molstruc.2019.127052 . hal-02376443

\section{HAL Id: hal-02376443 \\ https://hal.science/hal-02376443}

Submitted on 26 Nov 2019

HAL is a multi-disciplinary open access archive for the deposit and dissemination of scientific research documents, whether they are published or not. The documents may come from teaching and research institutions in France or abroad, or from public or private research centers.
L'archive ouverte pluridisciplinaire HAL, est destinée au dépôt et à la diffusion de documents scientifiques de niveau recherche, publiés ou non, émanant des établissements d'enseignement et de recherche français ou étrangers, des laboratoires publics ou privés. 


\title{
A structural study of a polymer-surfactant system in dilute and entangled regime: Effect of high concentrations of surfactant and polymer molecular weight
}

\author{
Ahmed El Aferni ${ }^{a}$, Moez Guettari ${ }^{\text {a, }{ }^{*}, \text { Marwa Kamli }}{ }^{\text {a, b }}$, Tahar Tajouri ${ }^{\text {a }}$, Alain Ponton ${ }^{\mathrm{c}}$ \\ ${ }^{\text {a } U n i v e r s i t y ~ o f ~ T u n i s, ~ P r e p a r a t o r y ~ I n s t i t u t e ~ f o r ~ E n g i n e e r i n g ~ S t u d i e s ~ o f ~ T u n i s, ~ N M R ~ i n ~ P o l y m e r s ~ a n d ~ C o m p o s i t e s ~ L a b o r a t o r y, ~ T u n i s i a ~}$ \\ ${ }^{\mathrm{b}}$ Faculty of Sciences of Tunis, Faculty of Mathematical, Physical and Natural Sciences of Tunis, Tunisia \\ ${ }^{c}$ Laboratory MSC, UMR 7057, Univ Paris Diderot-Paris 7, CNRS, Bât. Condorcet, CC 7056, 75205, Paris, Cedex 13, France
}

\section{A R T I C L E I N F O}

\section{Article history:}

Received 11 July 2019

Received in revised form 8 September 2019

Accepted 8 September 2019

Available online 9 September 2019

\section{Keywords:}

Polymer

Surfactant

Conductivity

Viscosity

Newtonian behavior

Pseudo-plastic behavior

\begin{abstract}
A B S T R A C T
In the polymer-surfactant system, increasing the concentration of surfactant leads to structural changes in surfactant micelles. This is expected to influence the polymer conformation in the dilute regime where polymer chains are singles and in the entangled regime where the polymer system is described by the blob concept. In this report, the effect of large Sodium bis(2-ethylhexyl) sulfosuccinate (AOT), surfactant concentrations on the conformation of two polyvinylpyrrolidone (PVP) molecular weight $\left(\mathrm{M}_{\mathrm{w}}=55000 \mathrm{~g} /\right.$ mol and $\mathrm{M}_{\mathrm{W}}=360000 \mathrm{~g} / \mathrm{mol}$ ) was discussed. In the first part, in the dilute regime, $C_{P V P}<C^{*}$ where polymer chains are considered isolated, the determination of PVP $\left(\mathrm{M}_{\mathrm{W}}=55000 \mathrm{~g} / \mathrm{mol}\right.$ and $\mathrm{M}_{\mathrm{W}}=360000 \mathrm{~g} / \mathrm{mol}$ ) intrinsic viscosity $[\eta]$ showed a coil to globule transition with the increase of temperature. Electrical conductivity measurements have shown the morphological transition (spherecylinder) of surfactant micelles with the increase of surfactant concentrations. The addition of AOT wormlike micelles revealed the expansion of PVP chains for the two molecular weight. In the second part, in PVP entangled regime, $C_{P V P} \simeq 16 C^{*}$ where overlapped polymer chains form molecular blobs, the addition of AOT wormlike micelles to PVP solutions doesn't affect the Newtonian behavior of PVP $\left(\mathrm{M}_{\mathrm{W}}=55000\right)$ and the pseudo-plastic behavior of PVP $\left(\mathrm{M}_{\mathrm{w}}=360000 \mathrm{~g} / \mathrm{mol}\right)$. However, AOT surfactant reinforces significantly the dynamic viscosity of PVP, $\eta$ for the two molecular weight. By fitting the PVP viscosity-temperature dependence with Fulcher-Tammann-Vogel law, the results showed that the more the surfactant is added, the stronger the PVP solution becomes, which proves that AOT cylindrical (wormlike) micelles presence enhances the solid character of PVP solutions.
\end{abstract}

(C) 2019 Published by Elsevier B.V.

\section{Introduction}

Efforts to investigate polymer-surfactant systems have attracted the attention of researchers for decades. Researchers have always tried to target the different physicochemical aspects related to materials based on polymer-surfactant systems. Among these aspects, the rheological behavior of these systems was a significant issue for scientists because of the correlation between their structure and their flow behavior [1-5]. The first studies of polymersurfactant systems have been focused on the mechanisms governing the interaction of neutral polymers such as polyvinylpyrrolidone (PVP), polyéthylèneoxyde (PEO) or polyethylene

\footnotetext{
* Corresponding author.

E-mail address: gtarimoez@yahoo.fr (M. Guettari).
}

glycol (PEG) with anionic surfactants, in particular, the sodium dodecyl sulfate (SDS) in aqueous medium [6-8]. Experimentally, these systems have been analyzed typically by viscometry, conductivity, various spectroscopic techniques such as light scattering Fluorescence molecular probe, Magnetic nuclear resonance [9-13] ... The results have always revealed the formation of polymersurfactant complexes, or the so-called polymer-bound micelles. This polymer-surfactant association was considered because of hydrophobic forces [14-21]. However, for various polymers that have polar groups on their structure, such as PVP ... attractive iondipole interaction was found to be an engine for this association $[22,23]$. These studies have targeted systems with low polymer and surfactant amounts in the vast majority of cases. As a result, there was still a lack of work focusing on large-scale polymer surfactant mixtures. In the latest research [24], we showed that the structure 


\begin{tabular}{|ll|}
\hline \multicolumn{2}{|c|}{ Nomenclature } \\
$C_{P V P}$ & PVP concentration $\left(\mathrm{g} / \mathrm{dm}^{3}\right)$ \\
$C_{P V P}^{*}$ & PVP overlapping concentration $\left(\mathrm{g} / \mathrm{dm}^{3}\right)$ \\
$C_{e}$ & Entanglement concentration of polymer \\
$C_{A O T}$ & AOT concentration $\left(\mathrm{g} / \mathrm{dm}^{3}\right)$ \\
{$[\eta]$} & PVP intrinsic viscosity $\left(\mathrm{dm}^{3} / \mathrm{g}\right)$ \\
$\tau_{C}$ & Contraction rate of PVP chain $(\%)$ \\
$\tau_{e}$ & Expansion rate of PVP chain $(\%)$ \\
$n_{e}$ & Number of stands forming an entanglement \\
$\phi$ & Flory constant \\
$R_{g, d i l u t e}$ & The radius of gyration of polymer in dilute regime \\
& (nm) \\
$\eta$ & Correlation length (Blob size) of polymer $(\mathrm{nm})$ \\
$\eta$ & PVP dynamic viscosity (Pa.s) \\
$n$ & Consistency index of polymer solution $\left(\right.$ Pa.s $\left.{ }^{\mathrm{n}}\right)$ \\
$\tau$ & Fluidity index of polymer solution \\
$A$ & Shear stress (Pa) \\
$T$ & Pre-exponential factor (Pa.s) \\
\hline
\end{tabular}

of PVP in semi-dilute regime is affected by spherical micellessurfactant complexation. In this context, the aim of this study is to initiate research into the structural properties of large-scale polymer-surfactant mixtures. In fact, for larger polymer concentrations, transition occurred from dilute regime, where every single chain acts separately, to semi-dilute regime, in which the chains are getting closer and interpenetrating and where the concept of correlation length have been introduced by De Gennes $[25,26]$ to be the key prediction to understand the structure of polymer chains in solution. Otherwise, several works [27-29] have reported that with more increase of polymer concentration, entanglements between polymers chains leads to the appearance of semi-dilute entangled regime, in which static and dynamic properties of polymer chains are described by other scaling laws [29]. In addition, even for the large surfactant concentrations, the surfactant molecules assembly can have several morphologies (spherical micelles, cylindrical micelles, hexagonal structures ...) [30-35] that necessarily influence their interactions with the polymer. For this reason, a detailed investigation of polymer-surfactant interaction in various concentration domains is of great importance. Possible Correlation between polymer-surfactant behavior in dilute and concentrated mixtures would be a relevant finding. For this reason, we aim in this paper to study and discuss the interaction of AOT anionic surfactant with a typical neutral polymer, PVP. In our research group, we have investigated intensively the PVP physical properties in binaries solvents mixtures, in which PVP exhibits structural transitions $[36,37]$. In addition, we have also analyzed the transport phenomena and the rheological behavior of AOT-based reverse micelles [37,38]. Indeed, it seems to be expected that the interaction PVP-AOT will affect the rheological behaviors of both AOT and PVP.

This work focus on the study of the effect of AOT wormlike micelles on PVP in the dilute and concentrated regime. Our work consists of 4 steps. Firstly, we use capillary viscometry to develop a conformational analysis of PVP in dilute regime under temperature variation. Secondly, conductivity measurements of AOT in water will be discussed. PVP-AOT system in water will be investigated in dilute regime of PVP with the addition of various AOT concentrations. To extend the study from the polymer dilute regime to its concentrated one, the effect of AOT wormlike micelles on the dynamic viscosity of PVP will be analyzed for two PVP molecular weights.

\section{Experimental}

\subsection{Materials}

\subsubsection{Sample preparation}

Sodium bis (2-ethylhexyl) sulfoccinate (AOT) (96\%) and PVP $(\mathrm{M}=360000 \mathrm{~g} / \mathrm{mol}, 55000 \mathrm{~g} / \mathrm{mol})$ were purchased from Sigma Aldrich (USA) and used without any additional purification, deionized water was used as a solvent. An electronic balance (OHUAS AS 200) of precision $0.00001 \mathrm{~g}$ was used for weighing the appropriate PVP and AOT quantity. Polymer-surfactant samples were prepared by the addition of PVP (AOT) to a well-defined aqueous solution of PVP (AOT).

\subsection{Methods}

\subsubsection{Capillary viscometer}

The viscosity measurements were performed with a semiautomatic Visco Clock (Schott Instruments) and an Ubbelohde glass capillary viscometer $\left(K=0.003 \mathrm{~mm}^{2} \mathrm{~s}^{-2}\right)$. A thermostatic bath type CT72/P was used to control $\left( \pm 0.1^{\circ} \mathrm{C}\right)$ the temperature of the sample. The viscosity was determined by measuring respectively the flow times of the pure solvent, $t_{0}$, and the solution, $t$. The viscometer was washed with distilled water. The flow times were measured with an accuracy of \pm 0.01 s and corrected by a constant parameter $\theta$, provided by the manufacturer. The corrected values, $t_{0}^{*}$ and $t^{*}$, were obtained by the following equations:

$t_{0}^{*}=t_{0}-\theta$

$t^{*}=t-\theta$

\subsubsection{Electric conductivity}

The electrical conductivity was carried out by a Consort C860 conductimeter with two Platine plate attachments electrodes operating at (9-15) V. DC. The cell calibration constant was $1 \mathrm{~cm}^{-1}$. A series of standard solutions of $\mathrm{KCl}$ with specific concentrations of known conductivity were used for the calibration. A thermostatic bath type CT72/P was used to control the temperature of the studied samples $( \pm 0.01 \mathrm{~K})$. The relative accuracy relating to the measures of the conductivity is of $1 \%$.

\subsubsection{Rheological measurements}

The rheological measurements of polymer solutions were performed by BROOKFIELD RST-CC rheometer. The sample cup FTKRST and spindle CCT-25 were used for the measurement of the steady viscosities of PVP in water solutions at the shear rate from 100 to $1000 \mathrm{~s}^{-1}$. The steady viscosities of PVP and PVP-AOT solutions were carried out at different temperature from $25^{\circ} \mathrm{C}$ to $60^{\circ} \mathrm{C}$. The temperature was monitored $\left( \pm 0.1^{\circ} \mathrm{C}\right)$ by a thermostatic bath type CT72/P.

\section{Results and discussions}

\subsection{PVP conformation in the dilute regime}

In the dilute regime of polymer solutions, the determination of polymer intrinsic viscosity has been always a crucial step in the study of polymer dimension evolution under the variation of thermodynamic parameters as well the interaction with other chemical entities [39]. Using capillary viscometry, this part's objective is to analyze the effect of temperature on PVP intrinsic 
viscosity in dilute regime for the two selected two molecular weights $\left(\mathrm{M}_{\mathrm{w}}=55000 \mathrm{~g} / \mathrm{mol}\right.$ and $\left.\mathrm{M}_{\mathrm{w}}=360000 \mathrm{~g} / \mathrm{mol}\right)$. Fig. 1 depicts the change of reduced viscosity versus PVP concentration $C_{P V P}$, for two PVP molecular weights (a) $\mathrm{M}_{\mathrm{w}}=55000 \mathrm{~g} / \mathrm{mol}$ and (b) $\mathrm{M}_{\mathrm{w}}=360000 \mathrm{~g} / \mathrm{mol}$. As we can see, the two curves exhibit a slope variation from a well-defined concentration, $C_{P V P}^{*}$, called the overlapping concentration. The fact that $C_{P V P}^{*}$ of PVP $\left(\mathrm{M}_{\mathrm{w}}=55000 \mathrm{~g} /\right.$ $\mathrm{mol})$ takes very huge values in comparison with those taken by PVP $\left(\mathrm{M}_{\mathrm{w}}=360000 \mathrm{~g} / \mathrm{mol}\right.$ ) (Table 1$)$ seems to be evident result since the more the polymer's chains are longer the more they overlap earlier. Besides, at $50^{\circ} \mathrm{C} C_{P V P}^{*}$ decreases for both two PVP molecular weights. We can attribute this behavior to the change in solvent's quality at higher temperature. Therefore, hydrophobic effects enhance greatly which brings the chains closer together.

Typically, above $C_{P V P}^{*}$, the polymer-polymer interactions intensify, however, below $C_{P V P}^{*}$, the interchain interactions are so weak. We used the Huggins law [40] to determine the intrinsic viscosity of PVP, $[\eta]$ for two different temperatures, $25^{\circ} \mathrm{C}$ and $50^{\circ} \mathrm{C}$ as follows:

$\eta_{r d}=[\eta]+K_{H}[\eta]^{2} C_{P V P}$

where, $\eta_{r d}$ is the reduced viscosity of PVP in water. $K_{H}$ is the Huggins constant which measures the polymer-solvent affinity, its value permits therefore to describe the evolution of polymer
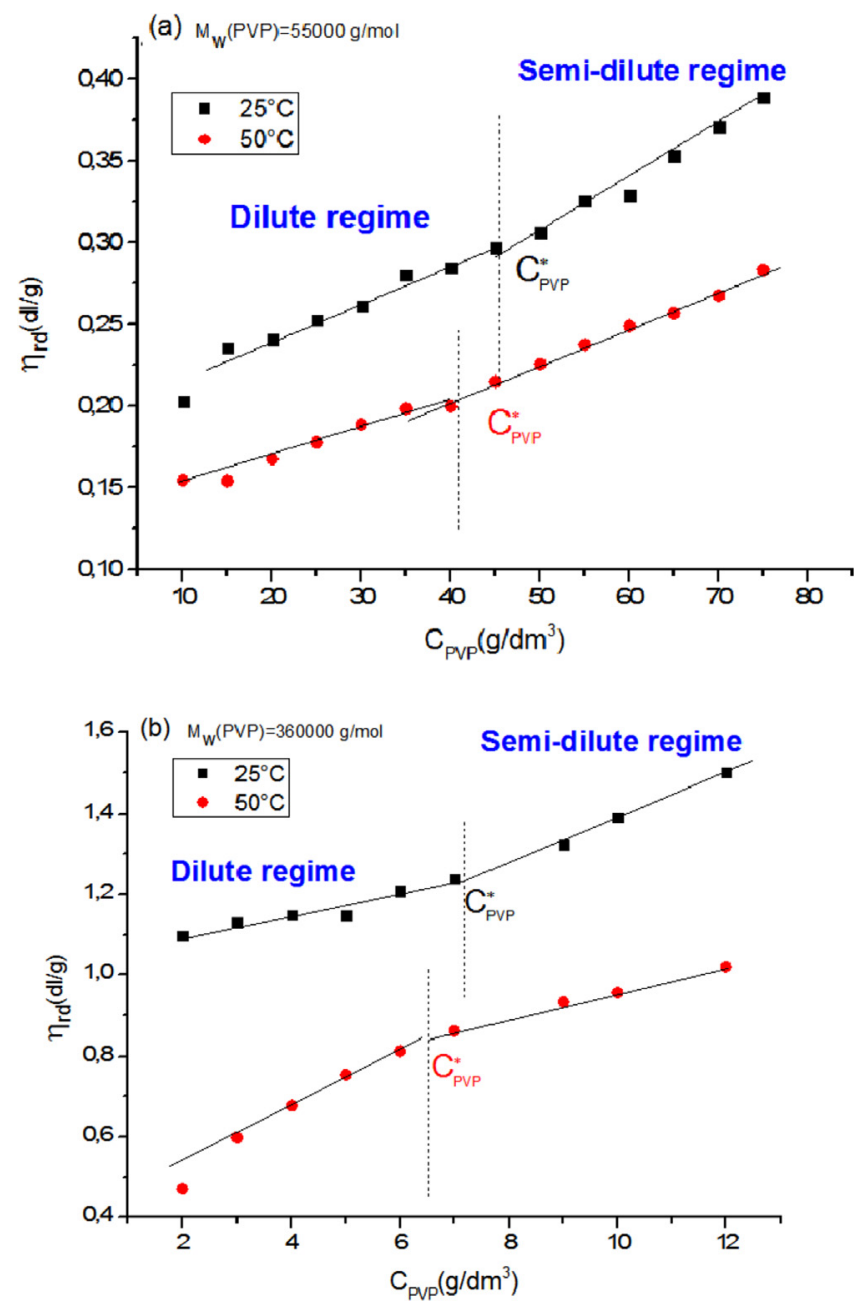

Fig. 1. Reduced viscosity versus PVP concentration $C_{P V P}$, for two PVP masses (a) $\mathrm{M}_{\mathrm{w}}=55000 \mathrm{~g} / \mathrm{mol}$ and (b) $\mathrm{M}_{\mathrm{w}}=360000 \mathrm{~g} / \mathrm{mol}$.
Table 1

Intrinsic viscosity of PVP $\left(\mathrm{M}_{\mathrm{w}}=55000\right.$ and $\left.\mathrm{M}_{\mathrm{w}}=360000 \mathrm{~g} / \mathrm{mol}\right)$ at $25^{\circ} \mathrm{C}$ and $50^{\circ} \mathrm{C}$.

\begin{tabular}{lllll}
\hline $\mathrm{M}_{\mathrm{w}}(\mathrm{g} / \mathrm{mol})$ & 55.000 & & 360.000 & \\
\hline $\mathrm{T}\left({ }^{\circ} \mathrm{C}\right)$ & 25 & 50 & 25 & 50 \\
$C_{P V P}^{*}\left(\mathbf{g} / \mathbf{d m}^{3}\right)$ & 52.2 & 40.6 & 7.0 & 6.3 \\
{$[\eta]\left(\mathbf{d m}^{\mathbf{3}} / \mathbf{g}\right)$} & 1.9 & 1.3 & 10.1 & 3.3 \\
$C_{P V P}^{*}[\eta]$ & 0.99 & 0.52 & 0.70 & 0.20 \\
$\boldsymbol{K}_{\boldsymbol{H}}$ & 0.34 & 1.05 & 0.30 & 7.09 \\
$\tau_{c}(\%)$ & 31.57 & & 67.32 & \\
\hline
\end{tabular}

conformation. Indeed, when $K_{H}<0.5$, the polymer-solvent interactions are attractive and the solvent is good. However, for the bad solvent case, the polymer-solvent interactions are repulsive if $0.5<K_{H}<1$. The polymer chains aggregate for high Huggins constant values, $K_{H}>1$. We have exposed the results obtained in Table 1 for the two PVP studied molecular weights.

The reduction of PVP intrinsic viscosity with rising temperature (Table 1) reflects a decrease in polymer chains size. We quantified this reduction by using the following equation to calculate the volume contraction rate $\tau_{e}$ :

$\tau_{c}=100\left|\frac{[\eta]_{25^{\circ} \mathrm{C}}-[\eta]_{50^{\circ} \mathrm{C}}}{[\eta]_{25^{\circ} \mathrm{C}}}\right|$

The values found are $67.32 \%$ and $31.57 \%$ respectively for $\mathrm{M}_{\mathrm{W}}=360000$ and $\mathrm{M}_{\mathrm{w}}=55000$. The contraction of the PVP chains is a sign of a Coil-globule conformation transition of PVP chains under the temperature increase. This can be explained by the change of solvent quality at higher temperature. In addition, the contraction rate is sensitive to polymer molecular weight.

\subsection{AOT structure in water}

It is well known that electric conductivity measurements present a powerful method to detect structural transitions of surfactant assembly in binary mixtures (or ternary systems surfactant/ polar (apolar) solvent, microemulsions ...) [41,42]. Therefore, we used this technique to detect the behavior of AOT assembly in water for various surfactant concentrations. Fig. 2 shows the AOT-specific conductivity, $\sigma$ logarithmic plot dependence on AOT concentration, which was performed at $25^{\circ} \mathrm{C}$. The curve obtained shows 3 regions with 3 different slopes. A critical AOT concentration separates all regions. This behavior shows the variation of the conductive species in the solution by moving from one regime to another. Indeed, the transition from the first to the second regime is characterized

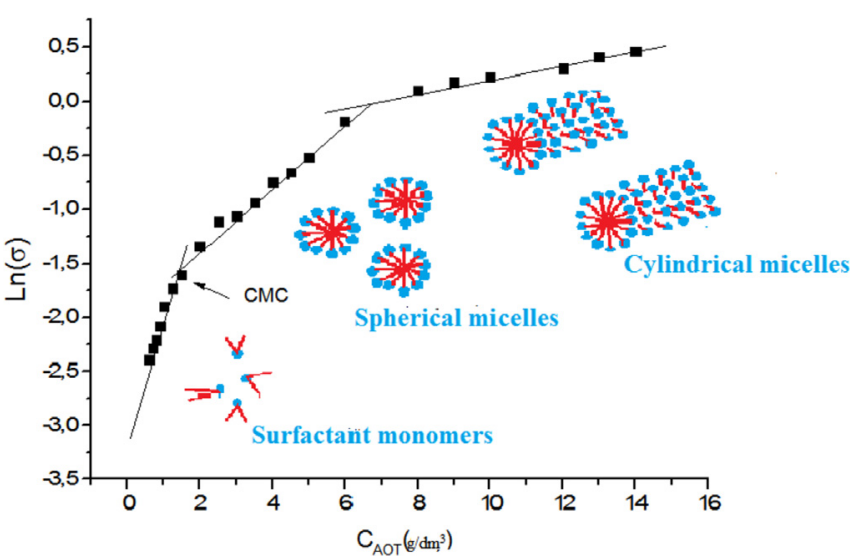

Fig. 2. Logarithmic plot of AOT specific conductivity versus AOT concentration, $C_{A O T}$ at $25^{\circ} \mathrm{C}$. 
by the critical micellar concentration of AOT in water, CMC. Its value $\left(\mathrm{CMC}=1.4 \mathrm{~g} / \mathrm{dm}^{3}\right)$ is in good agreement with the bibliography values [32]. Above this concentration, the conductive species are spherical micelles of AOT. The slope changes again by increasing the concentration of AOT $\left(7 \mathrm{~g} / \mathrm{dm}^{3}\right)$, thus, marking the transition to the third regime in which the conductive species ' morphology varies again. Several literature reports suggest that increasing the concentration of surfactants after CMC can lead to variations in micellar morphology. Micelles adopt cylindrical morphologies (Fig. 2).

\subsection{Effect of AOT on PVP conformation in the dilute regime}

Previously [23], we have studied the effect of AOT monomers and spherical micelles on the PVP intrinsic viscosity. Results revealed the formation of PVP-AOT complex via electrostatic and hydrophobic forces. The effect of AOT cylindrical micelles on PVP conformation was analyzed by the extrapolating the PVP reduced viscosity in the presence of AOT (Fig. 3). Thus, we have determined the intrinsic viscosity of PVP $\left(\mathrm{M}_{\mathrm{W}}=55000 \mathrm{~g} / \mathrm{mol}\right.$ and $\mathrm{M}_{\mathrm{W}}=360000 \mathrm{~g} / \mathrm{mol}$ ) in the presence of 4 high AOT concentrations $\mathrm{C}_{\mathrm{AOT}}\left(\mathrm{g} / \mathrm{dm}^{3}\right)=6,8,10$ and 12 . As can be seen from Fig. 4, the PVP intrinsic viscosity increase greatly for the two studied molecular weights (Table 2). Thus, the interaction between PVP chains and AOT micelles leads to the expansion of PVP single chain. We can attribute this effect to the rise of electroviscous effects due to the charged anionic micelles. This increase further confirms the formation of the PVP-AOT complex even between the AOT cylindrical
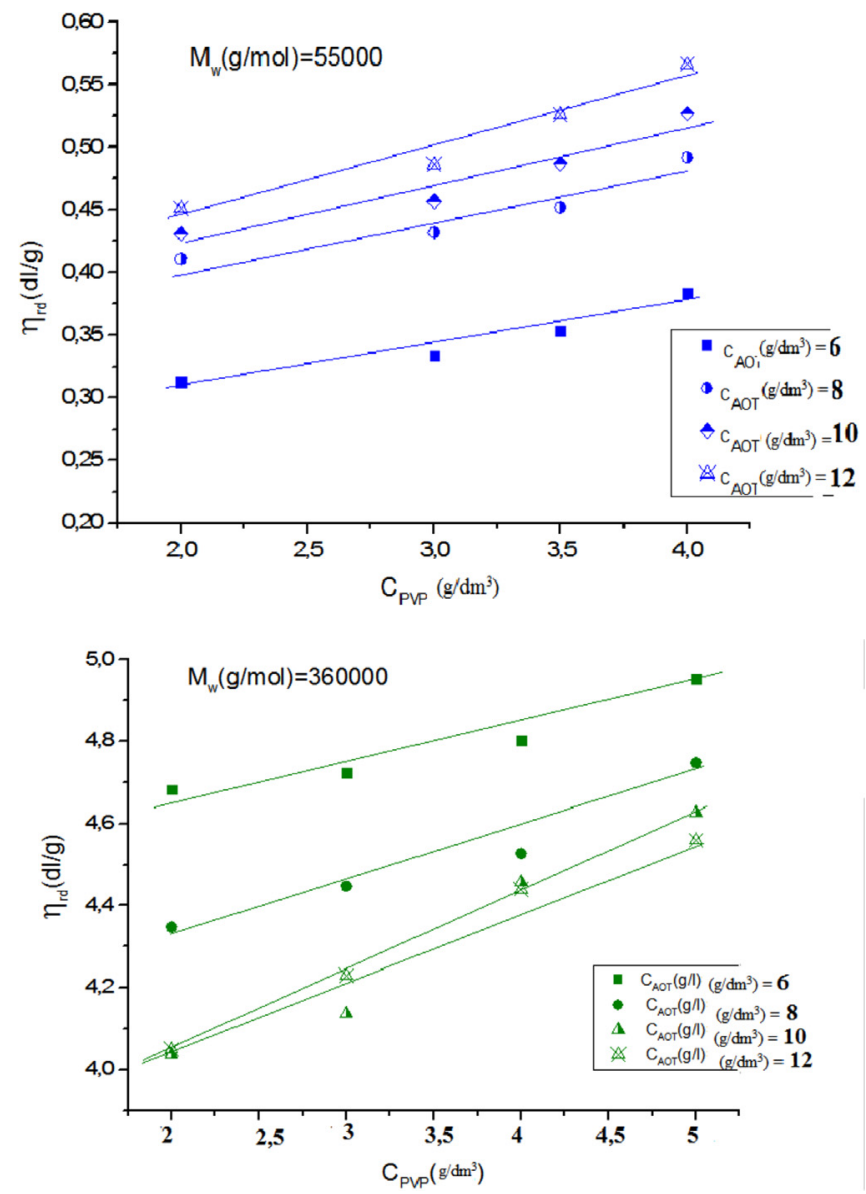

Fig. 3. Reduced viscosity of PVP $(M w=55000$ and $M w=360000)$ in the presence of various AOT concentrations.

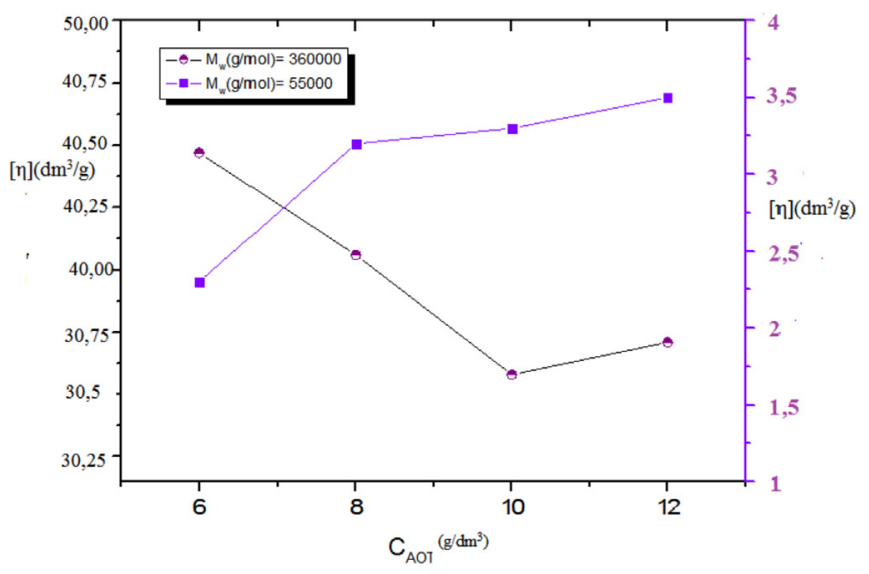

Fig. 4. $P V P$ intrinsic viscosity versus AOT concentration for two PVP mass ( $M_{w}$ (g/ $\mathrm{mol})=55000$ and 360000$), C_{A O T}$ at $25^{\circ} \mathrm{C}$.

Table 2

Intrinsic viscosities, Huggins constants and expansion rates of PVP $\left(\mathrm{M}_{\mathrm{W}}=55000\right.$ and $\mathrm{M}_{\mathrm{w}}=360000 \mathrm{~g} / \mathrm{mol}$ ) at $25^{\circ} \mathrm{C}$.

\begin{tabular}{llll}
\hline $\mathrm{C}_{\mathrm{AOT}}\left(\mathrm{g} / \mathrm{dm}^{3}\right)$ & {$[\eta]\left(\mathrm{dm}^{3} / \mathrm{g}\right)$} & $K_{H}$ & $\tau_{\exp }(\%)$ \\
\hline $\mathrm{M}_{\mathrm{w}}(\mathrm{g} / \mathrm{mol})=360000$ & & & \\
$\mathbf{0}$ & 10.1 & 0.33 & - \\
$\mathbf{6}$ & 44.7 & 0.04 & 343.37 \\
$\mathbf{8}$ & 40.6 & 0.07 & 302.88 \\
$\mathbf{1 0}$ & 35.8 & 0.16 & 254.68 \\
$\mathbf{1 2}$ & 37.1 & 0.12 & 267.33 \\
$\mathbf{M}_{\mathbf{w}}(\mathrm{g} / \mathbf{m o l})=\mathbf{5 5 0 0 0}$ & & & \\
$\mathbf{0}$ & 1.9 & 0.34 & - \\
$\mathbf{6}$ & 2.3 & 0.60 & 25.71 \\
$\mathbf{8}$ & 3.2 & 0.35 & 72.23 \\
$\mathbf{1 0}$ & 3.3 & 0.42 & 73.67 \\
$\mathbf{1 2}$ & 3.5 & 0.52 & 73.52 \\
\hline
\end{tabular}

micelles and the polymer chains. We have calculated the expansion rate $\tau_{\exp }$ of PVP chains as a function of AOT concentration for the two molecular weights according to the following equation:

$\tau_{\exp }=\left|\frac{[\eta]\left(C_{A O T}\right)-[\eta]}{[\eta]}\right| 100$

where $[\eta]$ and $[\eta]\left(C_{A O T}\right)$ are respectively the intrinsic viscosity of PVP in the absence and the presence of AOT. The results found are listed in Table 2. The expansion rate values prove clearly discern that cylindrical micelles expand more greatly PVP $\left(\mathrm{M}_{\mathrm{W}}=360000 \mathrm{~g} / \mathrm{mol}\right)$ in comparison with PVP $\left(\mathrm{M}_{\mathrm{W}}=55000 \mathrm{~g} / \mathrm{mol}\right)$. In the other side, upon the enhance of AOT concentrations, the intrinsic viscosity of PVP $\left(\mathrm{M}_{\mathrm{w}}=55000 \mathrm{~g} / \mathrm{mol}\right)$ continue its increase. However it decreases slightly for PVP $\left(M_{W}=360000 \mathrm{~g} / \mathrm{mol}\right)$. This suggests that the PVP $\left(M_{\mathrm{W}}=360000 \mathrm{~g} / \mathrm{mol}\right)$ chains are shrinking with the addition of more surfactant. This behavior can be explained by a screening effect because of the increase of counter-ions in solution. The screening effect in polymer-surfactant systems was discussed in previous report [43], it was called "a self-screening effect". The absence of such screening for PVP $\left(M_{W}=55000 \mathrm{~g} / \mathrm{mol}\right)$ suggests that electrostatic interactions between polymer and surfactant are sensitive to the monomers number of polymer chain. Moreover, the values obtained of Huggins constant $K_{\mathrm{H}}$ in the presence of various AOT concentrations show a decrease for $M_{w}=360000 \mathrm{~g} / \mathrm{mol}$ which is a signature of high solvent quality and attractive PVP-solvent interactions, Nevertheless, this trend decrease with the rise of AOT in solution which confirms the screening effect appearance. For $\mathrm{M}_{\mathrm{W}}=55000 \mathrm{~g} / \mathrm{mol}$, All the obtained values are, at the vicinity of 
$K_{\mathrm{H}}=0.5$, reflecting a good solvent behavior.

\subsection{Rheology of concentrated PVP in water}

\subsubsection{Effect of temperature}

In Fig. 5, we reported the two rheograms, viscosity versus shear rate (100-1000) $\mathrm{s}^{-1}$, of PVP in water for a temperature range $\left(25^{\circ} \mathrm{C}-60^{\circ} \mathrm{C}\right)$. The selected PVP concentrations were respectively $\mathrm{C}_{\mathrm{PVP}}=16 \mathrm{C}^{*}=100 \mathrm{~g} / \mathrm{dm}^{3}$ for PVP $\left(\mathrm{M}_{\mathrm{W}} 360000 \mathrm{~g} / \mathrm{mol}\right)$ and $\mathrm{C}_{\mathrm{PVP}}=16 \mathrm{C}^{*}=740 \mathrm{~g} / \mathrm{dm}^{3}$ for PVP $\left(\mathrm{M}_{\mathrm{W}}=55000 \mathrm{~g} / \mathrm{mol}\right)$. The results showed that the two selected molecular weights had two different rheological behaviors. As can be seen in Fig. 5, viscosity of PVP with low molecular weight $\left(\mathrm{M}_{\mathrm{w}}=55000 \mathrm{~g} / \mathrm{mol}\right)$ remains constant with the increase of shear rate. This is typical Newtonian behavior that can be described by equation:

$\tau=\eta \gamma$

where $\tau$ is the shear stress, $\gamma$ is the shear rate and $\eta$ is the apparent viscosity of PVP solution. With the temperature rise, viscosity values decrease significantly from 25 to $45^{\circ} \mathrm{C}$ and decrease slightly for $50-60{ }^{\circ} \mathrm{C}$ range. Meanwhile, the viscosity of PVP with a higher molecular weight decreases with the increase in shear rate, which reflects the pseudo-plastic rheological behavior of this molecular
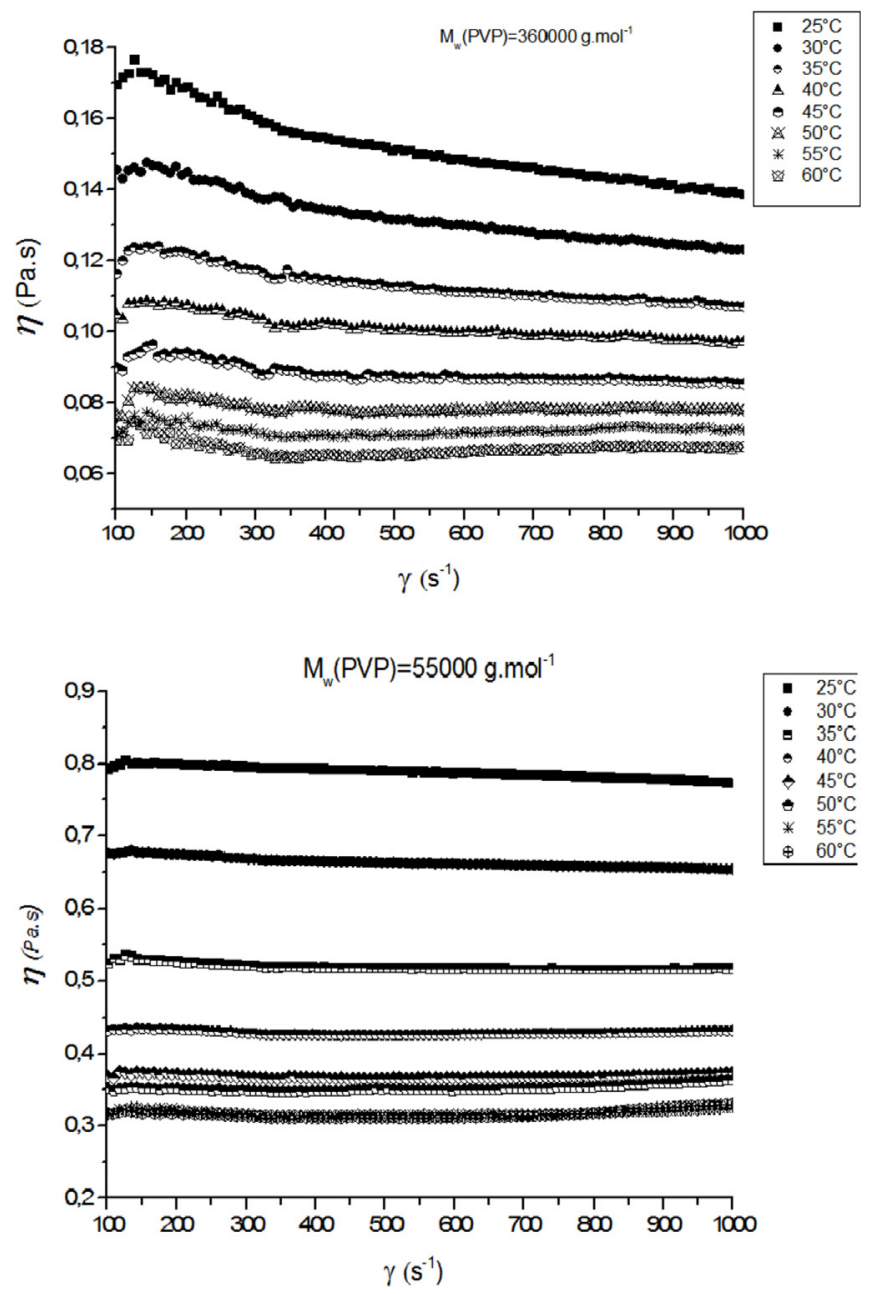

Fig. 5. Viscosity of PVP dynamic viscosity $\left(\mathrm{M}_{\mathrm{w}}(\mathrm{g} / \mathrm{mol})=55000,360000\right)$ as a function of shear rate at different temperatures. weight. Typically, the majority of synthetics polymers have shown a non-Newtonian rheological behavior in water [44]. This is because these fluids have a small flow resistance as the shear rate increases. Mathematically, this behavior can be modeled by a power-law model (Ostwald model) [53]:

$\tau=K \gamma^{n}$

$\eta=K \gamma^{n-1}$

where $\tau$ is the shear stress (Pa), $\gamma$ is the shear rate $\left(\mathrm{s}^{-1}\right), n$ is the flow behavior index (dimensionless). The lower $\mathrm{n}$, the more pronounced non-Newtonian flow, and $\mathrm{K}$ is the consistency index $\left(\mathrm{Pa} . \mathrm{s}^{\mathrm{n}}\right)$. In this rheological behavior, $\mathrm{K}$ traduces the solid aspect in the fluid. Thus, in a particular situation, $\mathrm{K}$ has been confused with the dynamic fluid viscosity studied, $\eta$.

\section{$n<1$ :Pseudo-plastic behavior \\ $n=1$ : Newtonian behavior \\ $n>1$ :Dilatant behavior}

For pseudo-plastic fluids, $n<1.0$. It should be noted that when $n=1$, equation (1) reduces to the Newtonian case. With the temperature increase, viscosity shows a similar trend of PVP (55000 g/ mol) (Fig. 5).

The different rheological behavior of PVP for the two molecular weights can be explained by the dependence of the polymer correlation length $\xi$, on the molecular weight at this concentration regime. De Gennes really expected that chains would begin to entangle at their overlap concentration $C^{*}$ [24]. This presumption was affected by the way that there is just an adjustment in powerlaw exponent for the concentration dependence of viscosity for neutral polymers in good solvent, in going from dilute to semidilute solution. All the solution properties in this model were described by the correlation length $\xi$ depending on the size of the polymer in the diluted regime [45].

$\xi=R_{g, \text { dilute }}\left(\frac{C}{C^{*}}\right)^{-3 / 4}$

where $\mathrm{C}$ and $\mathrm{C}^{*}$ are respectively the polymer concentration in the solution and overlap concentration. Given that the radius of gyration of PVP in the dilute regime $R_{G \text { dilute }}$ can be calculated from the Flory-Fox relationship which relies the radius of gyration of neutral polymer to its intrinsic viscosity $[\eta]$ as follows [46]:

$R_{g, \text { dilute }}^{3}=\frac{[\eta] M_{w}}{\phi}$

where $\mathrm{M}_{\mathrm{W}}$ is the polymer molecular weight and $\phi=3.110^{24}$, is the Flory constant. We have calculated the radius of gyration of two molecular weight of PVP at $25^{\circ} \mathrm{C}$ and $50^{\circ} \mathrm{C}$. Then, the correlation lengths of two PVP molecular weights $\xi_{360000}$ and $\xi_{55000}$ for PVP concentration $C=16 C^{*}$ were estimated according to equation (13). The found results were listed in Table 3 . We can notice the evident decrease of the correlation length with the molecular weights. Besides, a slight lowering was observed with the temperature rise that can be considered because of the change in solvent quality. It seems important also to note that since the correlation length $\xi$ is considered also as the blob size at this concentrated regime. Therefore, we can estimate the blob volume $\xi^{3}$ as reported in Table 3. It is interesting to highlight that at $50{ }^{\circ} \mathrm{C}$ the blob volume decrease by $64 \%$ for $M_{w}(g / m o l)=360000$ and $30 \%$ for $M_{w}(g /$ $\mathrm{mol})=55000$. Those contraction rates are in good agreement with 
Table 3

Radius of gyration in dilute regime and correlation length of PVP $\left(\mathrm{M}_{\mathrm{w}}=360000 \mathrm{~g} /\right.$ $\mathrm{mol}$ and $\mathrm{M}_{\mathrm{w}}=55000 \mathrm{~g} / \mathrm{mol}$ ) at $\mathrm{C}=16 \mathrm{C}^{*}$ at $25^{\circ} \mathrm{C}$ and $50^{\circ} \mathrm{C}$.

\begin{tabular}{lllll}
\hline & $R_{G, \text { dilute }}(\mathrm{nm})$ & $\xi(\mathrm{nm})$ & $\xi^{3}\left(\mathrm{~nm}^{3}\right)$ & $\xi_{360000} / \xi_{55000}$ \\
\hline $\mathbf{2 5}^{\circ} \mathbf{C}$ & & & & \\
$\mathbf{M}_{\mathrm{w}}(\mathbf{g} / \mathbf{m o l})=\mathbf{3 6 0 0 0 0}$ & 83.32 & 10.41 & 1128.10 & 2.90 \\
$\mathbf{M}_{\mathrm{w}}(\mathbf{g} / \mathbf{m o l})=\mathbf{5 5 0 0 0}$ & 28.72 & 3.59 & 46.26 & \\
$\mathbf{5 0}^{\circ} \mathbf{C}$ & & & & \\
$\mathbf{M}_{\mathrm{w}}(\mathbf{g} / \mathbf{m o l})=\mathbf{3 6 0 0 0 0}$ & 59.57 & 7.44 & 411.10 & 2.23 \\
$\mathbf{M}_{\mathrm{w}}(\mathbf{g} / \mathbf{m o l})=\mathbf{5 5 0 0 0}$ & 25.63 & 3.20 & 32.76 & \\
\hline
\end{tabular}

those of PVP intrinsic viscosity $[\eta]$ in dilute regime as it was founded in section 1 (67.32\% and 31.5\%).

Otherwise, this supposition was immediately brought up by Grassley et al. $[47,48]$ to be mistaken and it is proved that chain entanglement happens at concentration bigger than $C^{*}$. It has been called entanglement concentration $\mathrm{C}_{\mathrm{e}}$. (Scheme 1). Furthermore, in his work on diffusion of dilute and semi-dilute of PVP solutions, Burchard et al. [49] have studied by dynamic light scattering the diffusive behavior of PVP solutions with concentrations up to $\mathrm{C}_{\mathrm{PVP}}=6 \mathrm{C}^{*}$, they proved that at this concentrations range, solutions don't obey to the scaling equations predicted by de Gennes for semi-dilute regime of neutral polymer solutions. Thus, such results were attributed to the rise of chains-to-chains entanglement. The transition between unentangled and entangled regime affect considerably the solution viscosity [27].

In a more recent review report [27], Colby revealed that entanglement concentration could be estimated from overlapping concentration $C_{e} \approx 10 C^{*}$ for neutral polymer in a good solvent. Furthermore, Colby discusses also another parameter in relation with the entanglement, the number of overlapping strands forming an entanglement, $n_{e}$ (the number of overlapping chains necessary to form an entanglement) which showed a dependence with chain length, $N$.

$n_{e} \approx N^{-0.39}$

For the two studied PVP molecular weights $n_{e, 360000}$ and $n_{e, 55000}$ can be compared as follows:

$\left(\frac{n_{e, 36000}}{n_{e, 55000}}\right) \approx\left(\frac{N_{360000}}{N_{55000}}\right)^{-0.39}$

$n_{e, 360000} \approx 0.46 n_{e, 55000}$

Accordingly, at the studied concentration, $\mathrm{C}_{\mathrm{PVP}}=16 \mathrm{C}^{*}$, It seems obvious that the two molecular weights of the PVP show differences in the degree of entanglement. Indeed, this affects PVP

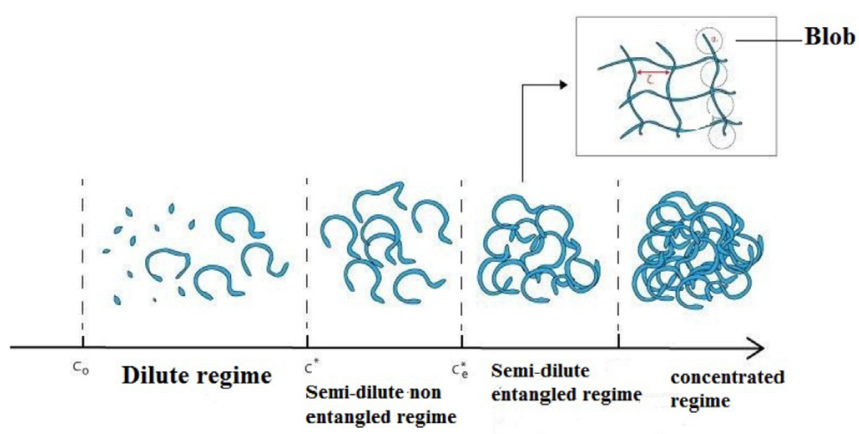

Scheme 1. Increased entanglement between chains with polymer concentration.
Table 4

Rheological Parameters (Consistency Index of Fluid, K, and Flow Behavior Index, n) of PVP in water solutions $(100 \mathrm{mg} / \mathrm{ml})$ and the root mean square error, $\mathrm{R}^{2}$, at Different Temperatures $\left(\mathrm{T}\left({ }^{\circ} \mathrm{C}\right)\right)$.

\begin{tabular}{lccc}
\hline $\mathrm{T}\left({ }^{\circ} \mathrm{C}\right)$ & $K$ & $n$ & $R^{2}$ \\
\hline 25 & 0.30 & 0.88 & 0.99 \\
30 & 0.23 & 0.90 & 0.99 \\
35 & 0.17 & 0.93 & 0.99 \\
40 & 0.13 & 0.94 & 0.99 \\
45 & 0.10 & 0.96 & 0.99 \\
50 & 0.07 & 0.99 & 0.99 \\
55 & 0.06 & 1.01 & 0.99 \\
60 & 0.05 & 1.02 & 0.99 \\
\hline
\end{tabular}

viscosity and solutions with two molecular weights, $\mathrm{M}_{\mathrm{w}}$ (g/ $\mathrm{mol})=55000$ and 360000 , respond differently under shear stresses.

We have summarized in Table 4 the values of the flow index $n$ and the consistency index $K$ of PVP (360000 g/mol) for the studied temperature range accompanied with the root mean square error, $\mathrm{R}^{2}$. The increase of $n$ toward 1 with the rise of temperature reflects a trend to Newtonian behavior. In addition, a decrease in fluid consistencyK was clearly discernible. It was found that consistency index $\mathrm{K}(360000 \mathrm{~g} / \mathrm{mol})$ varies in the same way with dynamic viscosity $(55000 \mathrm{~g} / \mathrm{mol})$ as function of temperature (Fig. 6). The transition toward Newtonian fluid behavior of PVP at higher temperature can be correlated to the contraction of PVP chains at this temperature range and the change in solvent quality from good solvent to bad solvent. Typically, for linear variation with temperature, fluids viscosity is described by Arrhenius law [50]. However, shown as the viscosity versus temperature plots in Fig. 6, variation of both dynamic viscosities, $\eta\left(\mathrm{M}_{\mathrm{W}}=55000 \mathrm{~g} / \mathrm{mol}\right)$ and consistency index, $K\left(\mathrm{M}_{\mathrm{W}}=360000 \mathrm{~g} / \mathrm{mol}\right)$ with increase of temperature shows nonlinear behavior, it is found that the temperature dependence of the dynamic viscosity in such cases can be frequently adjusted with the Fulcher-Tammann Vogel-law [51,52] as follows:

$\eta=A \exp \left(\frac{\beta}{T-T_{0}}\right)$

$K=A^{\prime} \exp \left(\frac{\beta^{\prime}}{T-T_{0}^{\prime}}\right)$

where the three adjustable parameters are $A\left(A^{\prime}\right)(\mathrm{Pa} \cdot \mathrm{s})$ is a preexponential factor, $\beta\left(\beta^{\prime}\right)(\mathrm{K})$ is the strength parameter known also as steepness index, is commonly used to classify forming materials as "strong" or "fragile" [51] and the temperature at zero mobility, $\mathrm{T}_{0}\left(T_{0}^{\prime}\right)(\mathrm{K})$. The VFTH equation with three parameters serves as the basis for the treatment of viscous systems and is able to model many viscous liquids in a wide temperature range. Fitting parameters at various AOT concentrations for the two PVP molecular weights are listed in Table 5. As we can see, the steepness index B takes very huge values for PVP $\mathrm{M}_{\mathrm{W}}=360000 \mathrm{~g} / \mathrm{mol}$ in comparison with PVP $\mathrm{M}_{\mathrm{w}}=55000 \mathrm{~g} / \mathrm{mol}$. The more the chain is long the more the concentrated PVP solutions are getting more hardness.

\subsubsection{Effect of surfactant}

Based on the results already seen for the effect of AOT surfactant on PVP viscosity in the diluted regime, where PVP chains act as individual units and inter-chain interactions are almost absent, we have observed that AOT significantly increases the intrinsic viscosity of PVP, which translates into an expansion of the PVP chain. Otherwise, the situation in the concentrated regime is more 

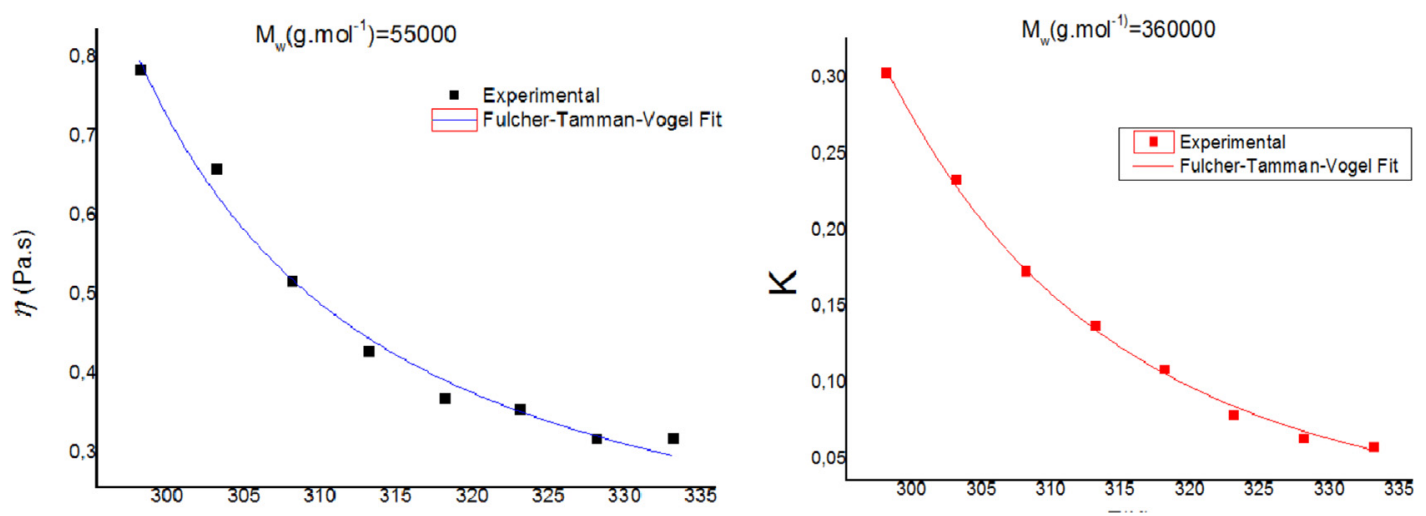

Fig. 6. Viscosity of PVP $\left(M_{w}(g / m o l)=55000\right)$ and consistency index of PVP $\left(M_{w}(g / m o l)=360000\right)$ as a function of temperature.

Table 5

Fulcher-Tammann Vogel fitting parameters at various AOT concentrations for the two PVP masses $\left(\mathrm{M}_{\mathrm{w}}=55000 \mathrm{~g} / \mathrm{mol}\right.$ and $\left.\mathrm{M}_{\mathrm{w}}=360000 \mathrm{~g} / \mathrm{mol}\right)$.

\begin{tabular}{|c|c|c|c|c|c|c|c|c|}
\hline \multirow[b]{2}{*}{$\mathrm{C}_{\mathrm{AOT}}(\mathrm{g} / \mathrm{l})$} & \multicolumn{4}{|c|}{$\mathrm{M}_{\mathrm{w}}(\mathrm{g} / \mathrm{mol})=55000$} & \multicolumn{4}{|c|}{$\mathrm{M}_{\mathrm{w}}(\mathrm{g} / \mathrm{mol})=360000$} \\
\hline & $A^{\prime}$ & $\beta^{\prime}$ & $\mathrm{T}_{0}^{\prime}$ & $\mathrm{R}^{2}$ & A & $\beta$ & $\mathrm{T}_{0}$ & $\mathrm{R}^{2}$ \\
\hline $\mathbf{0}$ & 0.10 & 79.45 & 259.69 & 0.98 & $5.23 \mathrm{E}-7$ & 3085.36 & 65.71 & 0.99 \\
\hline 6 & 0.0026 & 700.26 & 179.62 & 0.99 & 3.99E-6 & 1936.40 & 126.47 & 0.99 \\
\hline 8 & 0.0072 & 447.88 & 208.97 & 0.99 & $2.78 \mathrm{E}-8$ & 4775.15 & 7.48 & 0.98 \\
\hline 10 & 0.0068 & 514.29 & 198.21 & 0.98 & $9.65 \mathrm{E}-9$ & 5344.74 & -1.67 & 0.97 \\
\hline 12 & 0.0001 & 1535.50 & 129.02 & 0.99 & $1.46 \mathrm{e}-8$ & 4965.30 & 15.25 & 0.98 \\
\hline
\end{tabular}

complicated due to the entanglement of the polymer chains. Starting from this known situation, we have measured the dynamic viscosity of PVP in water $\left(\mathrm{M}_{\mathrm{W}}(\mathrm{g} / \mathrm{mol})=55000,360000\right)$ under shear rate in the presence of 4 different AOT concentrations, $\mathrm{C}_{\mathrm{AOT}}$ $\left(\mathrm{g} / \mathrm{dm}^{3}\right)=6 \approx 5 C M C$ where surfactant micelles are of spherical form and 8,10 and $12 \approx 10 C M C$ where surfactant micelles become cylindrical. Results are plotted in Fig. 7. It can be clearly seen that for both two molecular weights, PVP viscosity shows enormous grow. Meanwhile, we can discern from Fig. 7 that this increase in viscosity begins from $\mathrm{C}_{\mathrm{AOT}}=6 \mathrm{~g} / \mathrm{dm}^{3}$ for PVP with low molecular weight $\left(\mathrm{M}_{\mathrm{W}}\right.$ $(\mathrm{g} / \mathrm{mol})=55000)$, although, for PVP $\left(\mathrm{M}_{\mathrm{w}}(\mathrm{g} / \mathrm{mol})=360000\right)$, viscosity exhibits a slight at $\mathrm{C}_{\mathrm{AOT}}=6$ and $8 \mathrm{~g} / \mathrm{dm}^{3}$ and a significant rise for $C_{\mathrm{AOT}}=10$ and $12 \mathrm{~g} / \mathrm{dm}^{3}$. This difference between two molecular weights viscosity behaviors can be attributed to the difference in blob size between the two molecular weights as well as the degree of entanglement as discussed in the previous section. Otherwise, in the case of PVP $\left(\mathrm{M}_{\mathrm{W}}(\mathrm{g} / \mathrm{mol})=360000\right)$, viscosity increase with the addition of more AOT surfactant, this can be explained by a change in the morphology of the micelles from spherical form to cylindrical form. We reported in Fig. 8 the variation of the blob size $\xi$ values versus AOT concentrations. We discerned two different behaviors for each PVP weight. As a matter of fact, the increase of $\xi$ for PVP $\left(\mathrm{M}_{\mathrm{W}}=55000 \mathrm{~g} / \mathrm{mol}\right)$ with AOT concentration traduce the extension of PVP chains as well the PVP blobs due to the electrostatic repulsions between charged surfactant micelles. Nevertheless, for PVP $\left(\mathrm{M}_{\mathrm{w}}=360000 \mathrm{~g} / \mathrm{mol}\right)$, with the addition of more surfactant, PVP chains and blobs show a significant contraction. We considered such behavior as evident result of saturated PVP chains with AOT micelles; so, the more addition of micelles can lead to the appearance of a screening effect of highly charged medium. Thus, these results are consistent with those found in a diluted regime where the electroviscous effects of surfactants are better felt by the big molecular weight.

Surfactant assembly may present morphological transitions at these higher compositions (from spherical to cylindrical micelles)
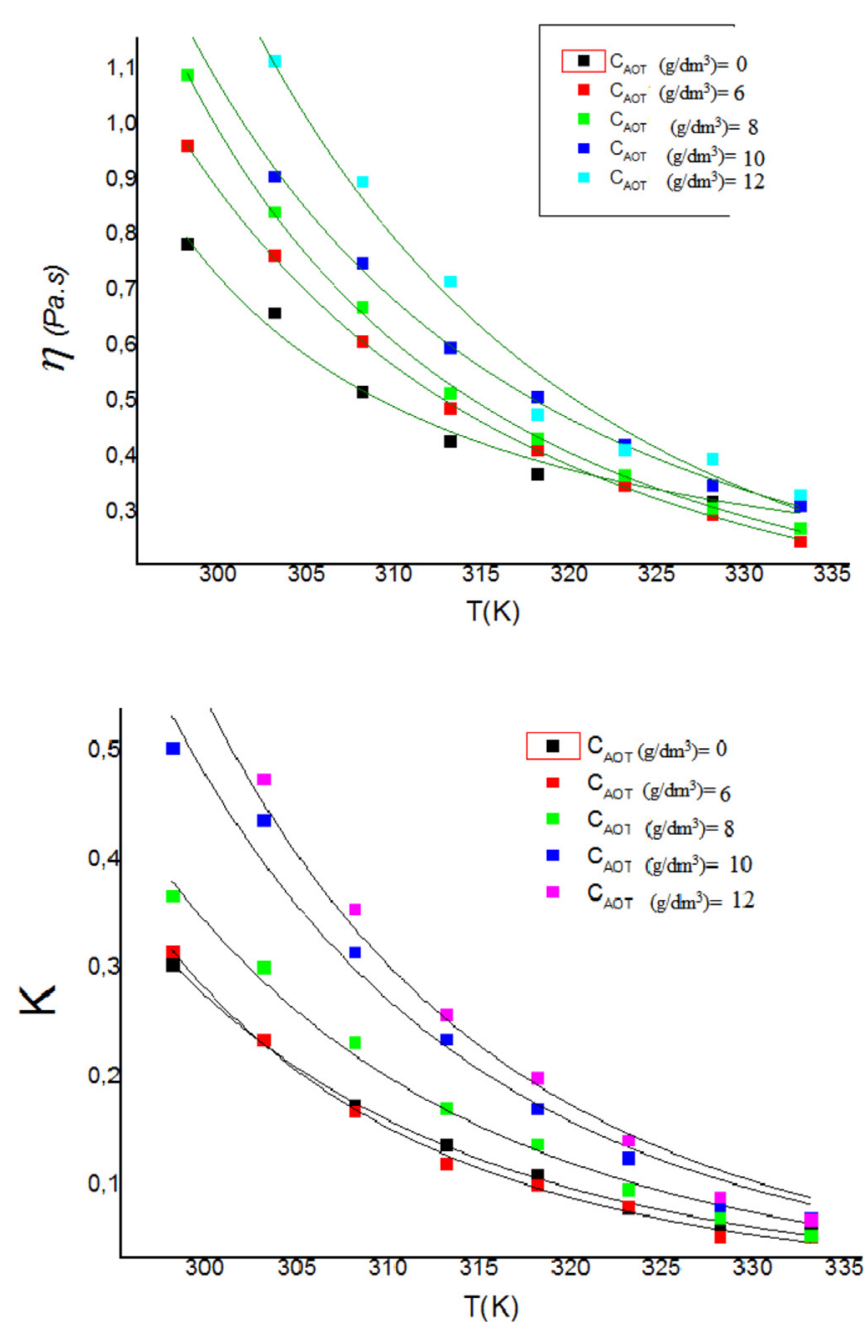

Fig. 7. Viscosity of PVP dynamic viscosity $\left(\mathrm{M}_{\mathrm{w}}(\mathrm{g} / \mathrm{mol})=55000,360000\right)$ as a function of shear rate at different AOT concentrations at $25^{\circ} \mathrm{C}$.

[29-31]. In Fig. 9, we have reported the variation of the consistency index $K$ and the fluid index $n$ versus the surfactant content, it is clear that $K$ increases with the addition of more surfactant, particularly, at $\mathrm{C}_{\mathrm{AOT}}=8,10$ and $12 \mathrm{~g} / \mathrm{dm}^{3}$ where the morphology of AOT assembly changes from spherical to cylindrical. This confirms that surfactant enhances greatly the consistency of PVP solutions. Meanwhile, the addition of surfactant micelles did not result in a 


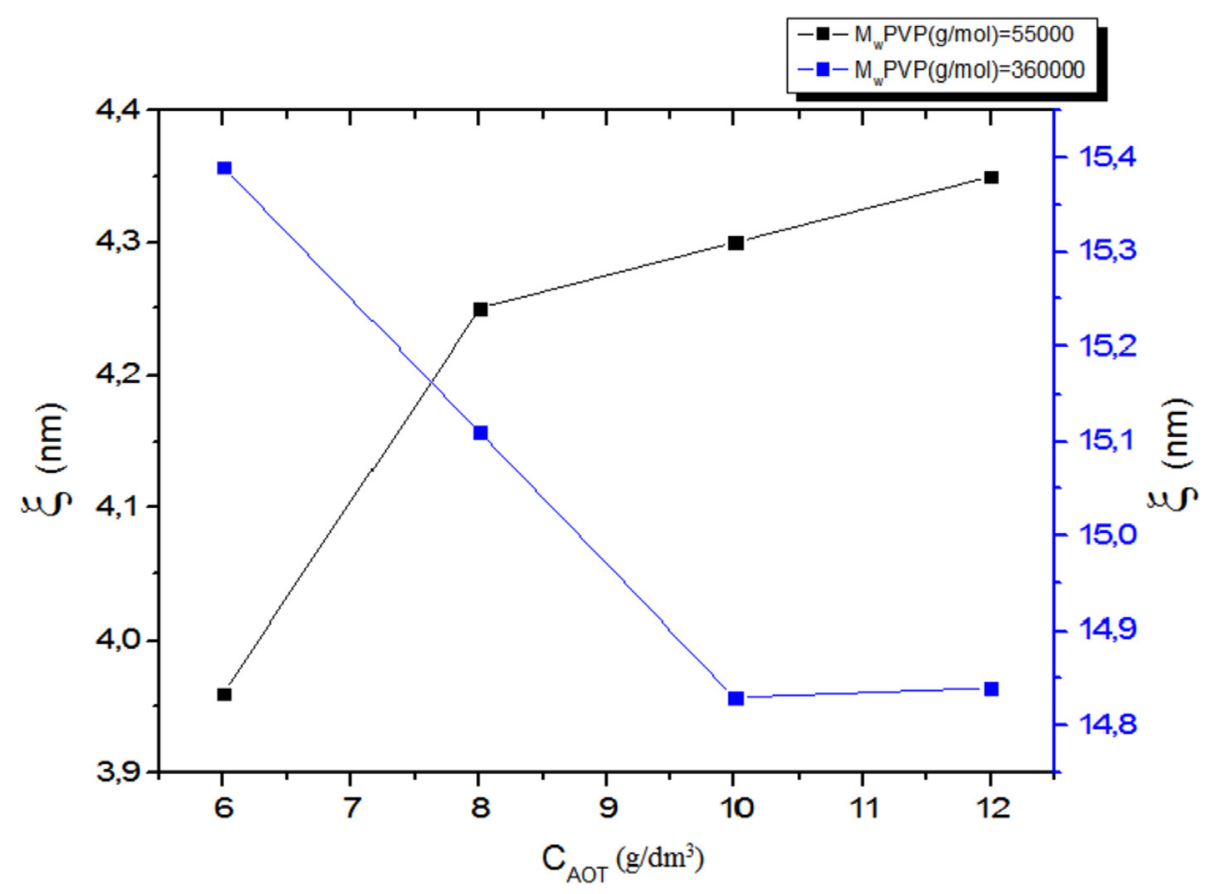

Fig. 8. The Blob size of PVP $\left(\mathrm{M}_{\mathrm{w}}(\mathrm{g} / \mathrm{mol})=55000,360000\right)$ as of different AOT concentrations at $25^{\circ} \mathrm{C}$.

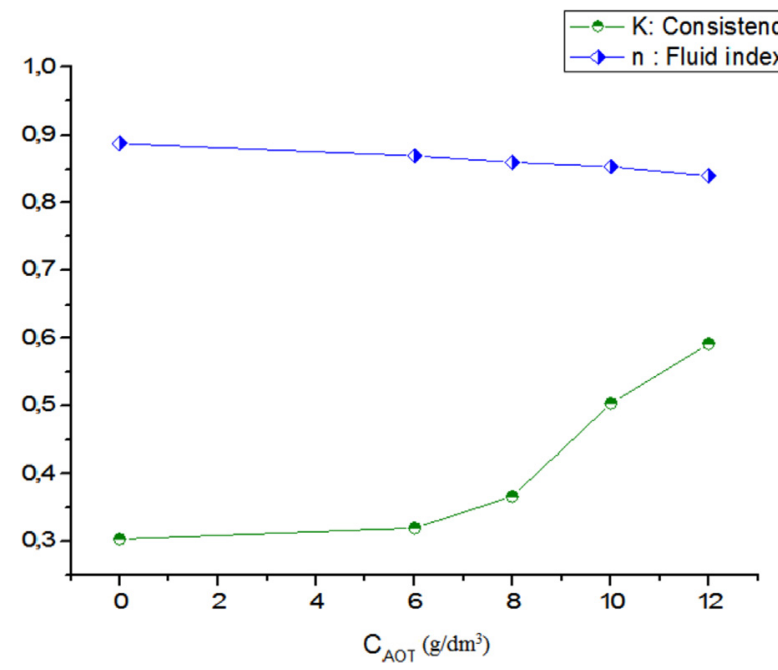

Fig. 9. Consistency index $\mathrm{K}$ and fluid index $\mathrm{n}$ of PVP $(\mathrm{Mw}(\mathrm{g} / \mathrm{mol})=360000)$ versus AOT concentrations at $25^{\circ} \mathrm{C}$.

significant change of fluidity index values $n$, we can distinguish from Fig. 9 that his value presents very slight decrease as we add more surfactant.

Furthermore, we have plotted in Fig. 10 the variation of dynamic viscosity $\left(\mathrm{M}_{\mathrm{W}}(\mathrm{g} / \mathrm{mol})=55000\right)$ and the consistency index $\mathrm{K}\left(\mathrm{M}_{\mathrm{W}}\right.$ $(\mathrm{g} / \mathrm{mol})=360000)$ versus temperature at the presence of different AOT concentration. By fitting the results with Fulcher-Tammann Vogel-law (Equation (14) and (15)), we have listed the different fit parameters in Table 5. As we can see, with the increase of AOT concentration, parameter $\beta$ increases, this increases the strength of PVP solutions, particularly for $\mathrm{M}_{\mathrm{w}}(\mathrm{g} / \mathrm{mol})=55000$. Otherwise, the enormous values are taken by $\beta$ parameter for $M_{w}(g /$ $\mathrm{mol})=360000$ compared to $\mathrm{Mw}(\mathrm{g} / \mathrm{mol})=55000$ reflect a more solid character of the highest molecular weight, consistent with the trend of the variation of the consistency index K.
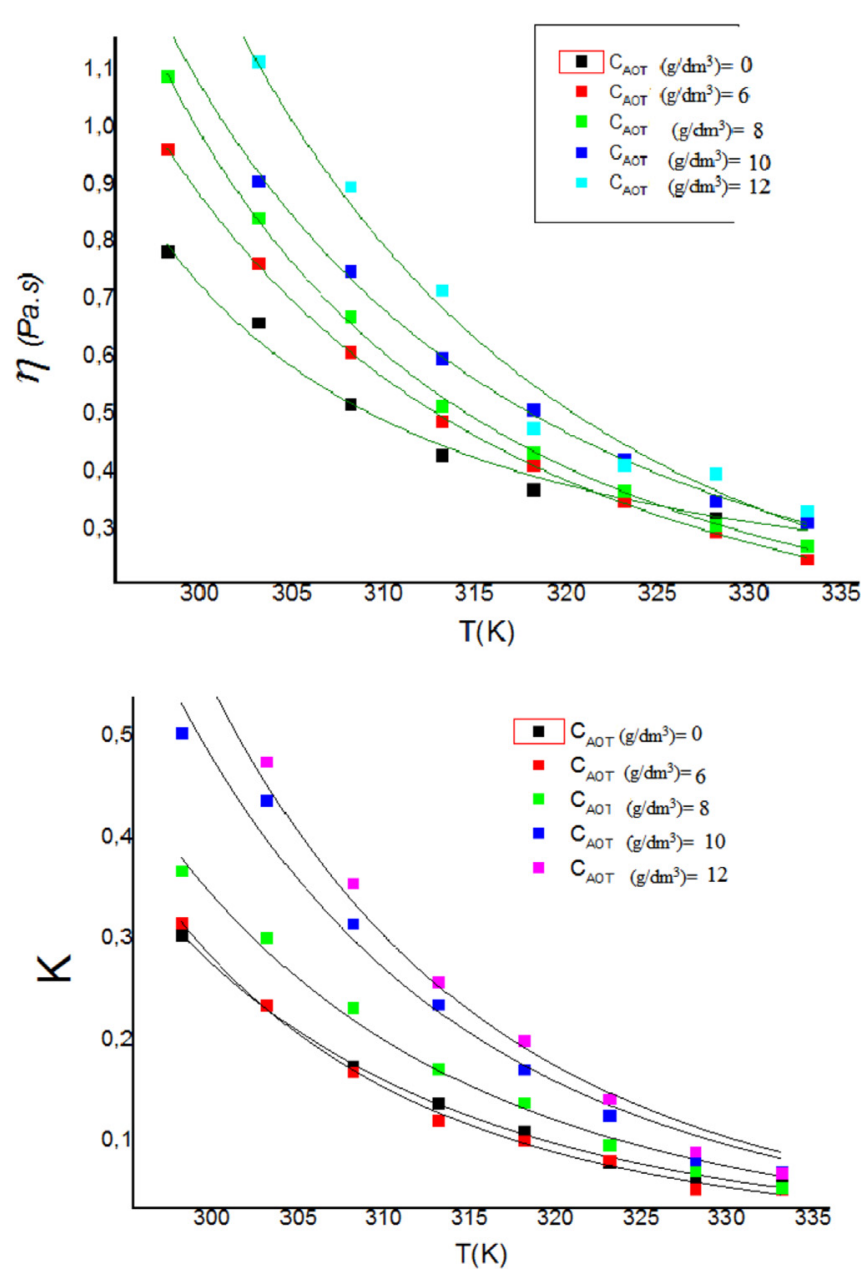

Fig. 10. Viscosity of PVP $\left(M_{w}(g / m o l)=55000\right)$ and Consistency index of PVP $\left(M_{w}(g /\right.$ $\mathrm{mol})=360000$ ) as a function of temperature at various AOT concentrations. 


\section{Conclusion}

At low surfactant concentrations, several previous reports have shown a consensus that anionic surfactant interacts with neutral polymers by a kind of complexation between the two entities. Meanwhile, very few studies have provided answers regarding the effect of the polymer conformation and surfactant structures on this interaction. In addition, these systems can behave differently in very concentrated polymer and surfactant regimes from their behavior in dilute regimes. In this paper, the experimental investigation of PVP-AOT system has provided valuables results.

* The conformation analysis in the dilute regime has shown that PVP adopts a Coil conformation for low temperatures and a globular conformation for high temperatures.

* Conductivity measurements have shown the existence of structural transition from spherical micelles to cylindrical micelles (wormlike micelles).

* In dilute regime, It was observed that AOT cylindrical assembly expand greatly the PVP chain dimension for the low molecular weight $\left(\mathrm{M}_{\mathrm{w}}=55000 \mathrm{~g} / \mathrm{mol}\right)$, Meanwhile, for higher molecular weight $\left(\mathrm{M}_{\mathrm{w}}=360000 \mathrm{~g} / \mathrm{mol}\right)$, PVP chains contract with the addition of AOT cylindrical micelles, the difference between the two molecular weight was attributed to the existence of screening effect for the high molecular weight.

* In the entangled polymer regime, PVP dynamic viscosity has shown different behaviors for the two studied molecular weights. A Newtonian rheological behavior for PVP with lower polymer molecular weights and pseudo-plastic behavior for PVP with higher molecular weight. This was explained by the difference in PVP correlation length between the two molecular weights at this concentration regime.

* In the entangled polymer regime, the addition of AOT cylindrical micelles enhances greatly the PVP dynamic viscosity for both two molecular weights.

* It was emphasized that PVP solutions acquire a more solid character for both molecular weights with the addition of AOT.

Nevertheless, despite interesting results found, this study can only be initiations to the detailed study of system properties in very high concentration regimes.

\section{Conflicts of interest}

Authors declare that there is no conflict of interest.

\section{Acknowledgments}

Financial support provided by CNRS (French) - DGRST(Tunisia) project,15R1301, is gratefully acknowledged.

\section{References}

[1] H.-M. Haake, F.E. Antunes, A. Böttcher, B. Lindman, B. Klotz, L. Alves, On the rheology of mixed systems of hydrophobically modified polyacrylate microgels and surfactants: role of the surfactant architecture, J. Colloid Interface Sci. 513 (2017) 489-496, https://doi.org/10.1016/j.jcis.2017.11.047.

[2] S. Aramideh, R. Borgohain, P.K. Naik, C.T. Johnston, P.P. Vlachos, A.M. Ardekani, Multi-objective history matching of surfactant-polymer flooding, Fuel 228 (2018) 418-428, https://doi.org/10.1016/j.fuel.2018.04.069.

[3] G.Q. Zhao, S.B. Chen, Nonlinear rheology of aqueous solutions of hydrophobically modified hydroxyethyl cellulose with nonionic surfactant, J. Colloid Interface Sci. 316 (2007) 858-866, https://doi.org/10.1016/j.jcis.2007.07.065.

[4] A. Das Burman, A.R.Das Ghosh, Behavior of cationic and anionic surfactants including bile salts in presence of hydroxy propyl cellulose (HPC), Journal of Nanofluids 14 (2014) 140-153.

[5] A.A. Dar, A. Garai, A.R. Das, S. Ghosh, Rheological and fluorescence investigation of interaction between hexadecyltrimethyl ammonium bromide an methyl cellulose in the presence of hydrophobic salts, J. Phys. Chem. A 114 (2010) 5083-5091.

[6] K. Chari, W.C. Lenhart, Effect of polyvinylpyrrolidone on the self-assembly of model hydrocarbon amphiphiles, J. Colloid Interface Sci. 137 (1990) 204-216, https://doi.org/10.1016/0021-9797(90)90057-U.

[7] M.N. Jones, The interaction of sodium dodecyl sulfate with polyethylene oxide, J. Colloid Interface Sci. 23 (1967) 36-42, https://doi.org/10.1016/00219797(67)90082-3.

[8] S. Saito, Solubilization properties of polymer-surfactant complexes, J. Colloid Interface Sci. 24 (1967) 227-234. https://doi.org/10.1016/0021-9797(67) 90225-1.

[9] W. Jiang, S. Han, Viscosity of nonionic polymer/anionic surfactant complexes in water, J. Colloid Interface Sci. 229 (2000) 1-5, https://doi.org/10.1006/ jcis.2000.6971.

[10] S. Dai, K.C. Tam, Laser light scattering and isothermal titration calorimetric studies of poly(ethylene oxide) aqueous solution in presence of sodium dodecyl sulfate, J. Colloid Interface Sci. 292 (2005) 79-85, https://doi.org/ 10.1016/j.jcis.2005.05.079.

[11] Y. Lu, L. Shi, X. Dong, R. Zhao, F. Xi, Z. Li, J. He, J. Liu, Aqueous synthesis of amphiphilic graphene quantum dots and their application as surfactants for preparing of fluorescent polymer microspheres, Colloids Surfaces A Physicochem. Eng. Asp. 563 (2018) 77-83, https://doi.org/10.1016/ j.colsurfa.2018.11.064.

[12] V.J. Sovilj, L.B. Petrović, Influence of molecular characteristics of nonionic cellulose ethers on their interaction with ionic surfactant investigated by conductometry, Colloid Polym. Sci. 284 (2005) 334-339, https://doi.org 10.1007/s00396-005-1376-4.

[13] F. Li, G.-Z. Li, G.-Y. Xu, H.-Q. Wang, M. Wang, Studies on the interactions between anionic surfactants and polyvinylpyrrolidone: surface tension measurement, 13C NMR and ESR, Colloid Polym. Sci. 276 (1998) 1-10, https:// doi.org/10.1007/s003960050201.

[14] S. Ghosh, S.P. Moulik, Clouding behaviours of binary mixtures of triton X-100/ tween-80 and tween-20/brij-35 and the influences of the ionic surfactants SDS and CTAB as well as the water soluble polymers PVA and PVP on their cloud points, Indian J. Chem. 38A (1999) 10-16.

[15] M. S Kumar, H. N Singh, The interaction of polyvinyl pyrrolidone (PVP) and triethanolamine dodecyl sulphate, J. Surf. Sci. Technol. 4 (1992) 381-387.

[16] S. Ghosh, S.P. Moulik, The behaviours of binary mixtures of polyoxyethylène (10) cethylether (Brij-56) with polyvinyl lalcohol (PVA)and methylcellulose (MC), Indian J. Chem. 38 (1999) 201-208.

[17] S. Das, S. Mondal, S. Ghosh, Interaction of cationic gemini surfactant tetramethylene-1,4 bis(dimethyl tetradecylammonium bromide) with anionic polyelectrolyte sodium carboxymethyl cellulose, with two different molar masses, in aqueous and aquo-organic (isopropanol) media, RSC Adv. 6 (2016) 30795-30803.

[18] T. Chakraborty, I. Chakraborty, S. Ghosh, Sodium carboxymethylcelluloseCTAB interaction: a detailed thermodynamic study of polymer-surfactant interaction with opposite charges, Langmuir 22 (2006) 9905-9913.

[19] E.D. Goddard, Polymer-surfactant interaction Part I. uncharged water-soluble polymers and charged surfactants, Colloids Surface. 19 (1986) 255-300, https://doi.org/10.1016/0166-6622(86)80340-7.

[20] S. Ghosh, A. Mal, T. Chakraborty, G.C. De, D.G. Marangoni, Interaction of a cationic surfactant with an oppositely charged polymer, J. Surf. Sci. Technol. 32 (2016) 107-114.

[21] D. Varade, R. Sharma, P. Majhi, P. Bahadur, Interaction of some water soluble polymers with ionic surfactants in water, J. Surf. Sci. Technol. 19 (2003) 85-100.

[22] P. Hansson, B. Lindman, Surfactant-polymer interactions, Curr. Opin. Colloid Interface Sci. 1 (1996) 604-613, https://doi.org/10.1016/S1359-0294(96) 80098-7.

[23] A. EL Aferni, M. Guettari, T. Tajouri, Effect of polymer conformation on polymer-surfactant interaction in salt-free water, Colloid Polym. Sci. 294 (2016) 1097-1106, https://doi.org/10.1007/s00396-016-3869-8.

[24] M. Kamli, M. Guettari, T. Tajouri, Structure of polyvinylpyrrolidone aqueous solution in semi-dilute regime: roles of polymer-surfactant complexation, J. Mol. Struct. 1196 (2019) 176-185. https://doi.org/10.1016/j.molstruc.2019. 06.069.

[25] P.G. De Gennes, Scaling Concept in Polymer Physics, Cornell University Press, 1979.

[26] F.B. Wyart, P.G. De Gennes, P HYSICAL J OURNAL E Viscosity at small scales in polymer melts 97 (2000) 93-97.

[27] H. Cottet, P. Gareil, J.L. Viovy, The effect of blob size and network dynamics on the size-based separation of polystyrenesulfonates by capillary electrophoresis in the presence of entangled polymer solutions, Electrophoresis 19 (1998) 2151-2162, https://doi.org/10.1002/elps.1150191219.

[28] D.C. Boris, R.H. Colby, Rheology of sulfonated polystyrene molecules, Macromolecules 31 (1998) 5746-5755.

[29] R.H. Colby, Structure and linear viscoelasticity of flexible polymer solutions: comparison of polyelectrolyte and neutral polymer solutions, Rheol. Acta 49 (2010) 425-442, https://doi.org/10.1007/s00397-009-0413-5.

[30] J.P. Rothstein, Strong flows of viscoelastic worlike micelle solutions, Rheol. Rev. (2008) 1-46.

[31] D.E.L.U. Pierre, E.T. Marie, C. Paris, Rhéologie des fluides complexes . Transitions de texture et de phases induites par le cisaillement : phases lamellaires et éponges de surfactant Aurélien Lèon To cite this version : HAL Id : tel- 
00000919 ECOLE NORMALE SUPERIEURE Laboratoire de Physique Statistique, 2002.

[32] D.C. Roux, J.-F. Berret, G. Porte, E. Peuvrel-Disdier, P. Lindner, Shear-induced orientations and textures of nematic living polymers, Macromolecules 28 (1995) 1681-1687, https://doi.org/10.1021/ma00109a047.

[33] T.H. Ito, K.J. Clinckspoor, R.N. De Souza, E. Sabadini, The thermal signature of wormlike micelles, J. Chem. Thermodyn. 94 (2016) 61-66, https://doi.org/ 10.1016/j.jct.2015.10.021.

[34] P.A. Kralchevsky, E.G. Pelan, K.D. Danov, S.D. Stoyanov, J.L. Cook, I.P. Stott Growth of wormlike micelles in nonionic surfactant solutions: quantitative theory vs. experiment, Adv. Colloid Interface Sci. 256 (2018) 1-22, https:// doi.org/10.1016/j.cis.2018.05.006.

[35] M. Guettari, A. Aschi, R. Gomati, A. Gharbi, Structural transition of a homopolymer in solvents mixture, Mater. Sci. Eng. C 28 (2008) 811-815, https:// doi.org/10.1016/j.msec.2007.10.025.

[36] M. Guettari, R. Gomati, A. Gharbi, Effect of temperature on cononsolvency of polyvinylpyrrolidone in water/methanol mixture, J. Macromol. Sci. Part B Phys. 49 (2010) 552-562, https://doi.org/10.1080/00222341003595378.

[37] M. Guettari, A.E.L. Aferni, T. Tajouri, Effect of micellar collisions and polyvinylpyrrolidone confinement on the electrical conductivity percolation parameters of water/AOT/isooctane reverse micelles, J. Mol. Struct. 1149 (2017) 712-719, https://doi.org/10.1016/j.molstruc.2017.08.026.

[38] M. Guettari, I. Ben Naceur, G. Kassab, T. Tajouri, Temperature effect on the inter-micellar collision and maximum packaging volume fraction in water/ AOT/isooctane micro-emulsions, J. Chem. Thermodyn. 95 (2016) 183-189, https://doi.org/10.1016/j.jct.2015.12.011.

[39] P.J. Flory, T.G. Fox, Treatment of intrinsic viscosities, J. Am. Chem. Soc. 73 (1951) 1904-1908, https://doi.org/10.1021/ja01149a002.

[40] L. Huggins, The viscosity of dilute solutions of long-chain molecules, J. Am. Chem. Soc. 64 (1942) 2716-2718.

[41] H. Gao, J. Li, B. Han, W. Chen, J. Zhang, R. Zhang, D. Yan, Microemulsions with ionic liquid polar domains, Phys. Chem. Chem. Phys. 6 (2004) 2914-2916, https://doi.org/10.1039/b402977a.

[42] S. Kumar, G. Singh, Navnidhi, T.S. Kang, M. Kaur, Thermally stable microemulsions comprising imidazolium based surface active ionic liquids, nonpolar ionic liquid and ethylene glycol as polar phase, J. Colloid Interface Sci.
511 (2017) 344-354, https://doi.org/10.1016/j.jcis.2017.10.025.

[43] E. Minatti, D.P. Norwood, W.F. Reed, Surfactant/polymer assemblies 2, Polyelectrolyte Properties Macromolecules 31 (1998) 2966-2971, 1-6.

[44] L.B. Petrovic, V.J. Sovilj, J.M. Katona, J.L. Milanovic, Influence of polymersurfactant interactions on o/w emulsion properties and microcapsule formation, J. Colloid Interface Sci. 342 (2010) 333-339, https://doi.org/10.1016/ j.jcis.2009.10.077.

[45] B. Duenweg, Polymer Solutions, JOHN WILEY \& SONS, INC., Publicatio, 2018 p. 281, https://doi.org/10.1021/ja01566a096.

[46] J.K. Armstrong, R.B. Wenby, H.J. Meiselman, T.C. Fisher, The hydrodynamic radii of macromolecules and their effect on red blood cell aggregation, Biophys. J. 87 (2004) 4259-4270, https://doi.org/10.1529/biophysj.104.047746.

[47] W.W. Graessley, Polymer chain dimensions and the dependence of viscoelastic properties on concentration, molecular weight and solvent power Polymer 21 (1980) 258-262, https://doi.org/10.1016/0032-3861(80)90266-9.

[48] R.S. Porter, J.F. Johnson, The entanglement concept in polymer systems, Chem. Rev. 66 (1966) 1-27, https://doi.org/10.1021/cr60239a001.

[49] W. Burchard, M. Eisele, Cooperative motion and self-diffusion IN dilute and semidilute poly-vinylpyrrolidone solutions, Pure \& Appi. Chem 56 (1984 1379-1390.

[50] L. Snoussi, A.A. Alarfaj, N.O. Alzamel, R.B.H. Kacem, N. Ouerfelli, M.A. Alkhaldi, N. Vrinceanu, Correlation Analysis of the viscosity Arrhenius-type equations parameters for some binary liquids mixtures, Mediterr. J. Chem. 6 (2017) 23, https://doi.org/10.13171/mjc62/01701041808-alarfaj.

[51] M.L.F. Nascimento, C. Aparicio, Data classification with the Vogel-FulcherTammann-Hesse viscosity equation using correspondence analysis, Phys. B Condens. Matter 398 (2007) 71-77, https://doi.org/10.1016 j.physb.2007.04.074

[52] C.A. Angell, Perspective on the glass transition, J. Phys. Chem. Solids 49 (1988 863-871, https://doi.org/10.1016/0022-3697(88)90002-9.

[53] C. Alvarez-Lorenzo, R. Duro, J.L. Gómez-Amoza, R. Martínez-Pacheco, C. Souto A. Concheiro, Influence of polymer structure on the rheological behavior of hydroxypropylmethylcellulose-sodium carboxymethylcellulose dispersions Colloid Polym. Sci. 279 (2001) 1045-1057, https://doi.org/10.1007/ s003960000463. 